\title{
Processing and immobilization of enzyme Ribonuclease A through laser irradiation
}

\author{
C. Popescu \\ National Institute for Lasers, Plasma and Radiations Physics, 77125 Bucharest, Romania \\ J. Roqueta \\ Consejo Superior de Investigaciones Científicas, Centre d'Investigacions en Nanociència i Nanotecnologia (CSIC- \\ CIN2), Campus UAB, 08193 Bellaterra, Spain
}

\begin{abstract}
A. Pérez del Pino
Consejo Superior de Investigaciones Científicas, Institut de Ciència de Materials de Barcelona (CSIC-ICMAB), Campus UAB, 08193 Bellaterra, Spain
\end{abstract}

M. Moussaoui and M. V. Nogués

Departament de Bioquímica i Biologia Molecular, Facultat de Biociències, Universitat Autònoma de Barcelona, 08193 Bellaterra, Spain

E. György ${ }^{\text {a) }}$

National Institute for Lasers, Plasma and Radiations Physics, 77125 Bucharest, Romania; and Consejo Superior de Investigaciones Científicas, Centre d'Investigacions en Nanociència i Nanotecnologia (CSIC-CIN2), Campus UAB, 08193 Bellaterra, Spain

(Received 7 July 2010; accepted 12 October 2010)

\begin{abstract}
We report the processing and immobilization of enzyme Ribonuclease A (RNase A) onto $\mathrm{SiO}_{2}$ glass collectors using the matrix assisted pulsed laser evaporation (MAPLE) technique.

The experiments were performed inside a stainless steel irradiation chamber. A pulsed UV $\mathrm{KrF}^{*}\left(\lambda=248 \mathrm{~nm}, \tau_{\mathrm{FWHM}} \approx 25 \mathrm{~ns}, v=10 \mathrm{~Hz}\right)$ excimer laser source was used for the irradiations. The laser fluence was varied in the range $0.4-0.7 \mathrm{~J} / \mathrm{cm}^{2}$. The morphology of the obtained films was investigated by atomic force microscopy (AFM) and their structure and composition by Fourier transform infrared spectroscopy (FTIR). The FTIR spectra of the films obtained from composite MAPLE targets consisting of $1 \%(\mathrm{w} / \mathrm{v})$ RNase A in Hepes-KOH $10 \mathrm{mM} \mathrm{pH} 7.5$ buffer exhibit the same bands as the spectrum of the initial, nonirradiated material. The enzymatic activity of the obtained structures was analyzed using synthetic substrate polycytidylic acid $(\operatorname{poly}(\mathrm{C}))$. The poly (C) cleavage by the immobilized enzyme and the products of formation were analyzed by means of reverse phase high performance liquid chromatography (HPLC).
\end{abstract}

\section{INTRODUCTION}

Bovine pancreatic Ribonuclease A (RNase A E.C. 3.1.27.5) is a well known endonuclease with a molecular weight of $13.7 \pm 0.3 \mathrm{kDa}$ that cleaves $3^{\prime}, 5^{\prime}$-phosphodiester linkages of single-stranded RNA when the base of the nucleotide in the $3^{\prime}$ position is a pyrimidine. ${ }^{1-4}$ It is know that some RNases, belonging to the RNase A family, have cytotoxic and/or cytostatic effects on cancer cells. ${ }^{5-}$ Therefore, the immobilization of these RNases on solid three-dimensional biocompatible and bioresorbable matrix materials could represent new solutions in cancer therapy by controlled drug release. ${ }^{8-10}$ The process, known as surface-mediated drug delivery, implies the release of therapeutic cargo from the surface of a biomaterial, typically an implant, to the surrounding cells,

\footnotetext{
a) Address all correspondence to this author.

e-mail: eniko.gyorgy@cin2.es

DOI: $10.1557 / j m r .2010 .55$
}

organs, and tissues. ${ }^{11}$ Among the advantages of this process are the spatial control of release of the therapeutic molecules and a more efficient delivery due to the much higher local concentration of drug available to the cells. $^{12,13}$

Enzymes can be immobilized onto an insoluble solid holder by various deposition techniques. However, the immobilization of complex organic molecules is not an easy task. Big differences between the initial material and the deposited structure's composition can emerge after the transfer and immobilization processes, leading to changes of chemical and biological properties such as stability and loss of enzymatic activity, which limit the practical applications of the immobilized structures. ${ }^{14}$

Laser techniques could become a possible approach for enzyme immobilization. Due to the use of light, there is a very low risk of cross-contamination, and the material transfer onto the desired holder has an accurate spatial resolution. Laser sources further offer the possibility of adjusting the quantity of the transferred and immobilized 
enzyme through the irradiation process parameters. ${ }^{15}$ Although high intensity laser pulses are destructive for organic materials, laser deposition techniques were optimized and a new method, called matrix assisted pulsed laser evaporation (MAPLE) was developed. In MAPLE, a frozen matrix consisting of a dilute solution of organic compound in a solvent material is used as a target for laser irradiation. ${ }^{16}$ At the same time, the intensity of the incident laser radiation is reduced up to one order of magnitude as compared to conventional pulsed laser deposition (PLD). This technique was successfully tested for immobilization onto solid holders of methoxy Ge triphenylcorrole, ${ }^{17}$ polypyrrole, ${ }^{18}$ polyethylene glycol derivatives, ${ }^{16,19,20}$ and polyalkylthiophene, ${ }^{21}$ and also several biomaterials such as horseradish peroxidase, insulin, ${ }^{22}$ bovine serum albumin, ${ }^{23}$ pepsine, ${ }^{24}$ silk fibroin, ${ }^{25}$ fibrinogen blood proteins, ${ }^{26}$ papain, ${ }^{27,28}$ creatinine,${ }^{29}$ and urease. ${ }^{30-32}$

An alternative laser technique, MAPLE direct write (MAPLE-DW) combines MAPLE with laser-induced forward transfer (LIFT). LIFT was developed for the transfer of inorganic materials, ${ }^{33-35}$ but later applied as MAPLE-DW beyond inorganics ${ }^{36}$ to organics as polymers, ${ }^{16}$ or living cells, ${ }^{16,37}$ where the material to be transferred is mixed in a laser-absorbent matrix and coated onto a support transparent to laser irradiation. Starting from LIFT, another technique, absorbing film assisted LIFT (AFA-LIFT) was developed to transfer proteins, ${ }^{38}$ DNA arrays ${ }^{39}$ or cells ${ }^{40,41}$ where the organic materials are spread on absorbing layers deposited on the surface of support plates transparent to the incident laser wavelength. It was also found that LIFT can be used to transfer and create micropatterns of biological molecules such as DNA and proteins without the assistance of any absorbing material. ${ }^{42}$

In this article we report the successful laser immobilization of the enzyme RNase A onto $\mathrm{SiO}_{2}$ glass collectors using the MAPLE technique. Our purpose was to find the maximum threshold fluence value that led to the formation of uniform and continuous thin films on the substrate surface, avoiding decomposition of the laser processed RNase A molecules. Under optimized irradiation conditions, the laser transferred RNase A preserved its molecular structure and enzymatic activity.

\section{EXPERIMENTAL DETAILS}

\section{A. Laser immobilization of RNase A}

The experiments were performed in a stainless steel irradiation chamber. A pulsed $\mathrm{UV} \mathrm{KrF}^{*}(\lambda=248 \mathrm{~nm}$, $\tau_{\mathrm{FWHM}} \approx 25 \mathrm{~ns}, v=10 \mathrm{~Hz}$ ) COMPexPro 205 excimer laser source was used for the irradiations. The laser pulse repetition rate was set at $10 \mathrm{~Hz}$. The laser fluence was set at values in the range $(0.4-0.7) \mathrm{J} / \mathrm{cm}^{2}$. The incidence angle of the laser beam on the target surface was $45^{\circ}$. During the experiment, the laser beam scanned the target surface at a constant velocity of $2 \mathrm{~mm} / \mathrm{s}$ to avoid drilling the target. The irradiated $X Y$ surface area was $1 \times 1 \mathrm{~cm}^{2} .1 .5 \times 10^{4}$ subsequent laser pulses were applied for the deposition of each film. Before each deposition experiment, the irradiation chamber was evacuated down to a residual pressure of $1.6 \times 10^{-2} \mathrm{~Pa}$. This pressure value was maintained during the RNase A thin film growth experiments.

Hepes-KOH $10 \mathrm{mM}$ pH 7.5 buffer was chosen for the preparation of the target solution. The enzyme concentration was $1 \%(\mathrm{w} / \mathrm{v})$. The solutions were frozen in liquid nitrogen and kept frozen during laser irradiation by circulation liquid of nitrogen inside a special double wall target holder. The complete MAPLE workstation was purchased from Surface Systems \& Technology GmbH \& Co KG, (Hückelhoven, Germany).

RNase A was immobilized onto $\mathrm{SiO}_{2}$ glass collectors that were placed on a plane parallel to the target surface at a separation distance of $5 \mathrm{~cm}$. Prior to introduction inside the deposition chamber, the collectors were carefully cleaned in a Transonic T 310 ultrasonic bath with acetone and ethanol. During MAPLE deposition, the collectors were kept at room temperature. Twin samples were prepared to verify the reproducibility of the deposition process. The samples were analyzed in terms of composition, surface morphology, and enzymatic activity in the presence of the analyte molecules.

\section{B. Characterization methods of immobilized RNase A}

The surface morphology of the deposited RNase A thin films were investigated by atomic force microscopy (AFM) in acoustic (dynamic) configuration with a 5100 apparatus from Agilent Technologies (Santa Clara, California). The chemical composition and bonding states between the elements were studied by Fourier transform infrared spectroscopy (FTIR) in the wavenumber $4000 \mathrm{~cm}^{-}$ ${ }^{1}$ to $500 \mathrm{~cm}^{-1}$ range, using a $4 \mathrm{~cm}^{-1}$ resolution Perkin Elmer Inc., Spectrum One apparatus (Wellesley, Massachusetts).

\section{Analysis of the RNase A enzymatic activity}

RNase activity was analyzed from the digestion of the polycytidylic [poly $(C)]$ substrate by the immobilized enzyme and separation of the products of the reaction by reverse phase HPLC. The obtained structure was submerged in $1 \mathrm{~mL}$ of a $2.5 \mathrm{mg} / \mathrm{mL}$ poly $(\mathrm{C})$ solution in $10 \mathrm{mM}$ Hepes-KOH pH 7.5 at $25^{\circ} \mathrm{C}$ for $1 \mathrm{~h}$. The products of the reaction were analyzed by injecting $50 \mu \mathrm{L}$ of the solution on a reverse phase HPLC column (Nova-Pak C18, Waters Corp. Milford, Massachusetts) equilibrated with solvent A [10\% ammonium acetate (w/v) and $1 \%$ acetonitril (v/v) in water].

The elution was carried out at a flow rate $1 \mathrm{~mL} / \mathrm{min}$ with an initial $10 \mathrm{~min}$ wash and 50 min linear gradient 
from $100 \%$ solvent A to $10 \%$ solvent A plus $90 \%$ solvent B [10\% ammonium acetate (w/v) and $11 \%$ acetonitril $(\mathrm{v} / \mathrm{v})$ in water]. ${ }^{43}$ The same process was used to analyze a blank set of samples as the control experiment. To this purpose, poly $(\mathrm{C})$ solution was incubated with $\mathrm{SiO}_{2}$ glass plates identical to those used as collectors for the RNase A immobilization by MAPLE. For positive control experiments, poly $(\mathrm{C})$ solution was incubated with nonirradiated RNase A powdered material.

\section{RESULTS AND DISCUSSION}

\section{A. Surface morphology investigations}

In Fig. 1 we present a top view AFM image of RNase A immobilized on $\mathrm{SiO}_{2}$ substrate at $0.4 \mathrm{~J} / \mathrm{cm}^{2}$ laser fluence. The deposited structure consists of nanoparticles formed most probably by coalescence of RNase A molecules during their transit from the target toward the substrate surface constituting a continuous film. Apart from the nanoparticles, larger particles of about $500 \mathrm{~nm}$ mean diameter and about $200 \mathrm{~nm}$ mean height are present in the film's structure. Both mean diameter and mean height of particles increases with the increase of the incident laser fluence (Fig. 2). At the highest laser fluence, $0.7 \mathrm{~J} / \mathrm{cm}^{2}$ [Fig. 2(b)], the film is practically covered by micrometric particles.

The presence of large, micrometer sized particulates on the surface of MAPLE deposited organic thin films were related, according to theoretical predictions, to droplet ejection from the target surface as a result of explosive evaporation or spallation mechanisms, ${ }^{44,45}$ termed cold laser ablation. ${ }^{46,47}$ This ablation process could explain the

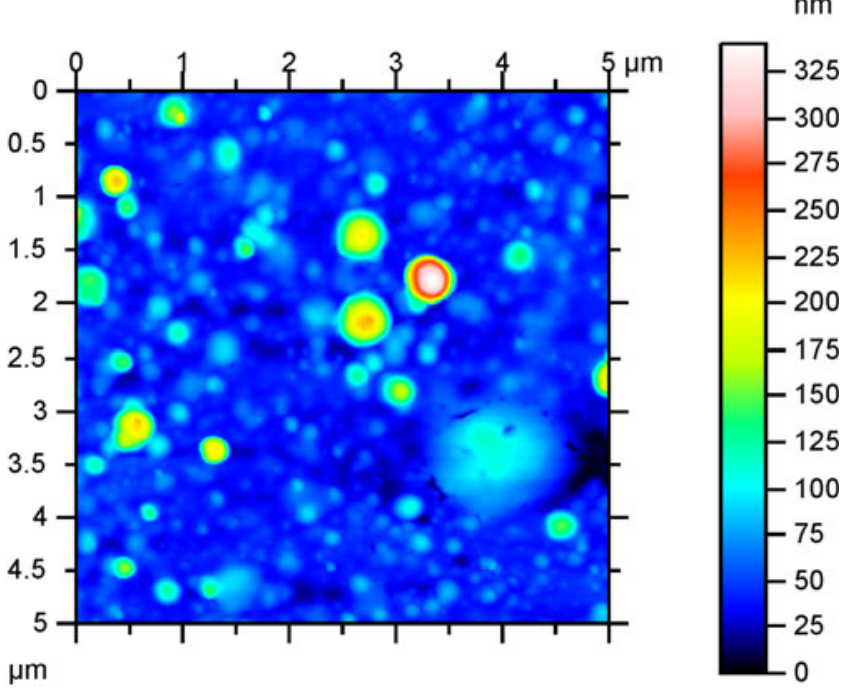

FIG. 1. Top view AFM image of the RNase A thin film obtained from a frozen composite target containing $1 \%(\mathrm{w} / \mathrm{v})$ biomaterial in buffer Hepes solvent, by irradiation with $1.5 \times 10^{4}$ subsequent laser pulses at $0.4 \mathrm{~J} / \mathrm{cm}^{2}$ laser fluence. increase of particle size and density resulting in a nonuniform surface morphology of the films with the increase of incident laser fluence. On the contrary, at low laser fluence, the surface morphology, constituted by tens of nanometer-sized particulates, can be assigned to surface evaporation and cluster formation. ${ }^{28}$

\section{B. Characterization of chemical composition}

To obtain information about the molecular structure of the deposited layers, the RNase A thin films were investigated by FTIR spectroscopy (Fig. 3I). The films spectra were compared with the spectrum of the nonirradiated RNase A base material used for the preparation of the composite targets (Fig. 3II). As can be observed, the spectra reproduce all the characteristic bands assigned to structural elements of RNase A, namely the amide A band
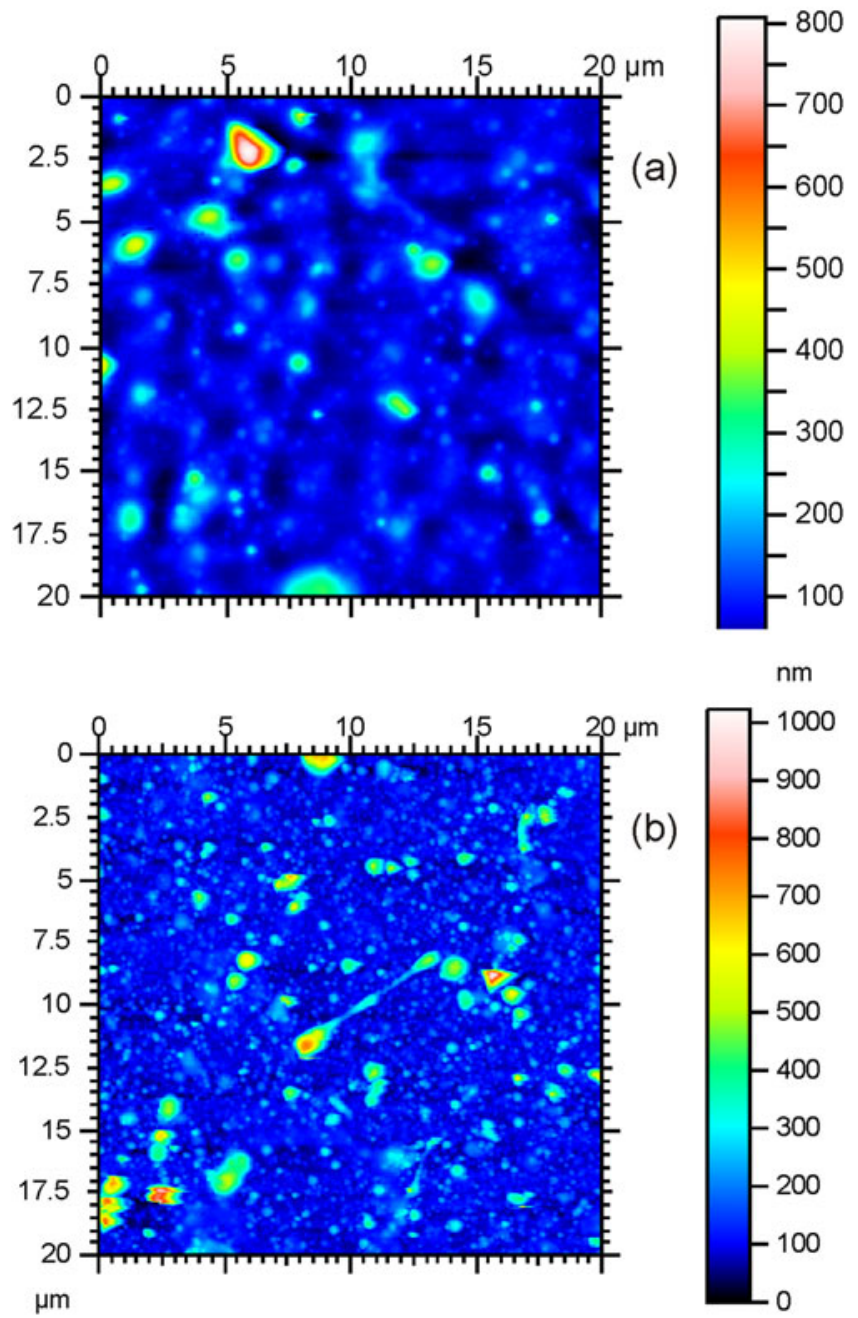

FIG. 2. Top view AFM images of the RNase A thin films obtained from a frozen composite target containing $1 \%(\mathrm{w} / \mathrm{v})$ biomaterial in buffer Hepes solvent, by irradiation with $1.5 \times 10^{4}$ subsequent laser pulses at (a) 0.5 and (b) $0.7 \mathrm{~J} / \mathrm{cm}^{2}$ laser fluence. 

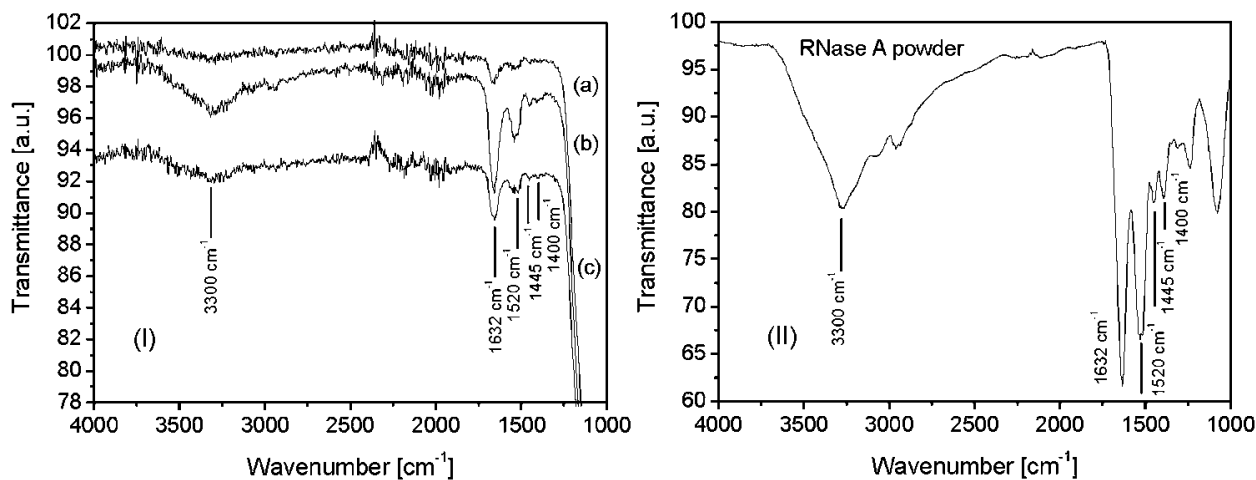

FIG. 3. FTIR spectra of (I) RNase A thin films obtained from a frozen composite target containing $1 \%$ (w/v) biomaterial in buffer Hepes solvent, by irradiation with $1.5 \times 10^{4}$ subsequent laser pulses at (a) 0.4 , (b) 0.5 , and (c) $0.7 \mathrm{~J} / \mathrm{cm}^{2}$ laser fluence and (II) nonirradiated RNase A base material used for the preparation of the composite targets.

around $3300 \mathrm{~cm}^{-1}$ due to $\mathrm{NH}$ stretching, the band at 1632 $\mathrm{cm}^{-1}$ of the amide $\mathrm{I}$ region due to $\mathrm{C}=\mathrm{O}$ stretching, the band at $1528 \mathrm{~cm}^{-1}$ attributed to tyrosine amino acid residues, the band at $1445 \mathrm{~cm}^{-1}$ of the amide II region attributed to $\mathrm{NH}$ bending, and $\mathrm{CN}$ stretching, and the band around $1400 \mathrm{~cm}^{-1}$ corresponding to a random structure. $^{48-50}$ The band at wavenumbers lower than around $1200 \mathrm{~cm}^{-1}$ corresponds to the glass substrate. ${ }^{28}$

For all fluences regimes, the spectra of the obtained RNase A films are similar to the base material spectrum, reproducing the same absorption bands. We would like to notice that according to differential scanning calorimetry analyses, ${ }^{51}$ thermal denaturation of RNase A takes place already at around $60{ }^{\circ} \mathrm{C}$. Thus, decomposition could be expected during the thin films growth, under the action of the subsequent laser pulses incident on the target surface. Nevertheless, as confirmed by FTIR results, the deposited thin films preserved the structure of the base material used for the targets preparation. This feature is an evidence of the effectiveness of the special precautions characteristic for the MAPLE technique, frozen composite target preparation procedure and reduction of the incident laser fluence values as compared to those used in conventional PLD.

The intensity of the bands in the FTIR spectra increases with the increase of the laser fluence from 0.4 to $0.5 \mathrm{~J} / \mathrm{cm}^{2}$ [Fig. 3I (a),(b)], most probably due to the increased amount of the enzyme molecules transferred to the collector surface. Nevertheless, the intensity of the bands decreases when the incident laser fluence was increased above $0.5 \mathrm{~J} / \mathrm{cm}^{2}$ [Fig. 3I (c)]. This feature was attributed to the decomposition of the RNase A molecules under action of higher intensity incident laser pulses. The value of $0.5 \mathrm{~J} / \mathrm{cm}^{2}$ was found as maximum threshold laser fluence value for which the spectra of the transferred and immobilized RNase A reproduce the bands of the nonirradiated base material, avoiding decomposition.

We analyzed the biomaterials solution of the composite targets before and after laser irradiation with different laser fluence values. To this purpose, drops from the

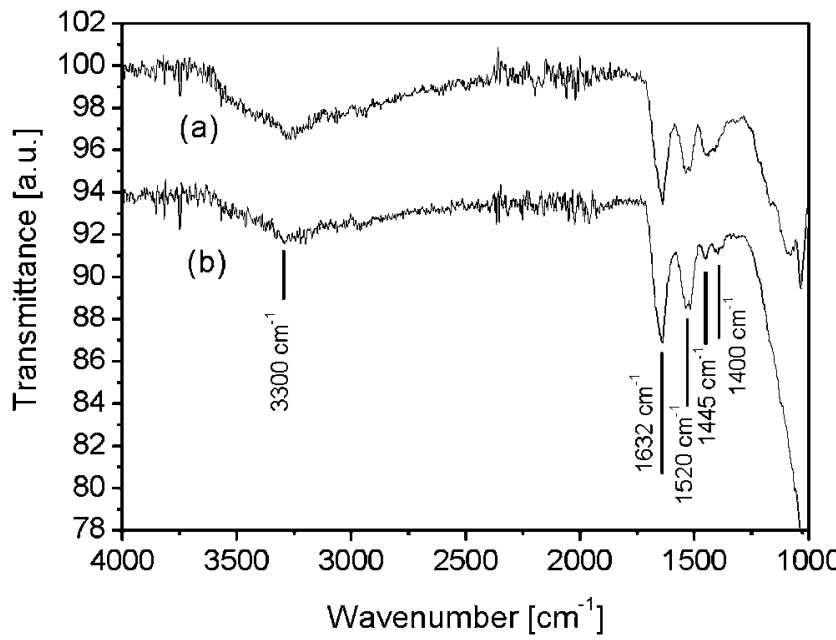

FIG. 4. FTIR spectra of the target containing $1 \%(\mathrm{w} / \mathrm{v})$ biomaterial in buffer Hepes solvent (a) before and (b) after laser irradiation at $0.5 \mathrm{~J} / \mathrm{cm}^{2}$ fluence.

nonirradiated and laser irradiated target solutions were deposited on glass substrates identical to those used for the laser immobilization of RNase A. The FTIR analyses were performed after the evaporation of the buffer Hepes solvent. The spectrum of the nonirradiated and laser irradiated target material with $0.5 \mathrm{~J} / \mathrm{cm}^{2}$ laser fluence are shown in Figs. 4(a) and (b), respectively. The spectrum of the irradiated material still reproduces the bands of the initial RNase A base powder, suggesting that chemical composition and structure of the biomaterial were preserved even at the identified maximum laser fluence threshold value.

\section{Enzymatic activity of the laser immobilized RNase A}

Fig. 5 shows the effect of the laser immobilized RNase $\mathrm{A}$ in the poly $(\mathrm{C})$ substrate [Fig. 5(A)] and the control corresponding to the blank set of samples [Fig. 5(B)]. As is 

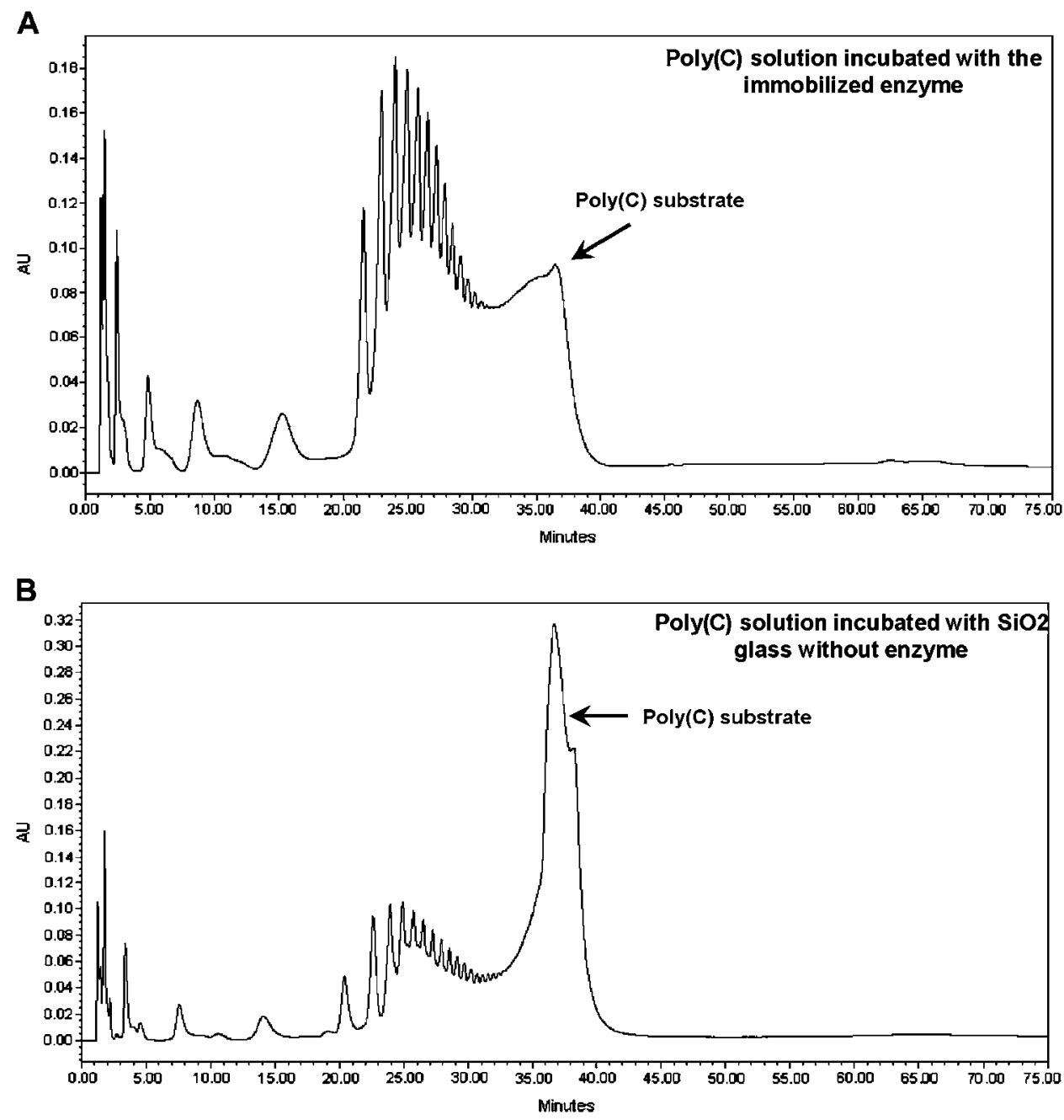

FIG. 5. Reverse phase HPLC separation of the products obtained from the polymeric poly(C) substrate by RNase A activity: the elution profiles of (A) the poly $(\mathrm{C})$ solution incubated with the RNase A enzyme immobilized at $0.5 \mathrm{~J} / \mathrm{cm}^{2}$ incident laser fluence and (B) the poly $(\mathrm{C})$ solution incubated with the $\mathrm{SiO}_{2}$ glass plate without enzyme. See Section II. C for details about the chromatographic procedure.

widely known, poly $(\mathrm{C})$ can be considered to be a synthetic analog of single-stranded RNA and is commonly used in research laboratories for the determination of RNase enzymatic activity. ${ }^{43}$ The immobilization of the RNase A was performed using the established optimum laser irradiation conditions, $0.5 \mathrm{~J} / \mathrm{cm}^{2}$ incident fluence on the composite target surface. The chromatographic profile corresponding to the products separation by reverse phase HPLC has previously been characterized. ${ }^{43}$ The last peak, with 38 min elution time, corresponds to the undigested poly $(\mathrm{C})$ substrate, a high molecular mass polymer. The digestion products, smaller molecular mass oligonucleotides, elute in order of increasing molecular mass, from mononucleotides to polynucleotides, as a function of elution time from 1 to $34 \mathrm{~min}$.

The profile corresponding to the $\operatorname{poly}(\mathrm{C})$ solution incubated with the immobilized enzyme [Fig. 5(A)] shows a large amount of low molecular mass digestion products and a reduced amount of the undigested poly $(\mathrm{C})$ substrate. This result proves the enzymatic activity of the immobilized RNase A. In addition, the product formation pattern is in agreement with the products obtained by RNase A in solution under the same conditions, ${ }^{43}$ indicating the preference for endonuclease activity. The control sample consisting of poly $(\mathrm{C})$ solution incubated with a $\mathrm{SiO}_{2}$ glass plates in the absence of RNase A [Fig. 5(B)] shows a large component corresponding to the high molecular mass undigested poly(C) substrate. The very low traces of smaller molecular mass components are due to a certain decomposition in time of the poly $(\mathrm{C})$ substrate. In the same elution time interval, the peak corresponding to the undigested poly $(\mathrm{C})$ substrate is nearly undistinguishable in the profile of the positive control sample.

\section{CONCLUSION}

RNase A was immobilized on $\mathrm{SiO}_{2}$ glass collectors in the form of continuous thin films by the MAPLE 
technique. The films consisted of nanoparticles formed most probably by coalescence of RNase A molecules and large, micrometer sized particles ejected directly from the target's surface. Both mean diameter and mean height of the particles increase with the increase of the incident laser fluence value. The FTIR spectra of the RNase A films were similar to the spectrum of the nonirradiated base material used for the preparation of the composite targets. The intensity of the bands increases with the increase of laser fluence until a maximum threshold value of $0.5 \mathrm{~J} / \mathrm{cm}^{2}$. At higher fluence values, the band intensity diminishes due to the decomposition of part of the transferred material under the action of laser pulses. The immobilization process does not affect the RNase A behavior, since the enzyme maintains for the polymeric poly $(\mathrm{C})$ substrate the cleavage pattern observed for the enzyme in solution.

\section{ACKNOWLEDGMENTS}

The authors acknowledge financial support from the Spanish National Research Council under Contract No. 2008601211 and the Romanian National University Research Council under Contract IDEAS No. 652.

\section{REFERENCES}

1. G. D'Alessio and J.F. Riordan: Ribonucleases: Structures and functions. (Academic Press, New York, 1997).

2. X. Parés, M.V. Nogués, R. de Llorens, and C.M. Cuchillo: Structure and function of ribonuclease A binding subsites. In Essays in Biochemistry, Vol. 26, edited by K.F. Tipton(Portland Press Ltd., London, 1991), pp. 89-103.

3. E. Battistel, D. Bianchi, and G. Rialdi: Thermodynamics of immobilized ribonuclease A. Pure Appl. Chem. 63, 1483 (1991).

4. R.T. Raines: Ribonuclease A. Chem. Rev. 98, 1045 (1998).

5. S.M. Rybak and D.L. Newton: Natural and engineered cytotoxic ribonucleases: Therapeutic potential. Exp. Cell Res. 253, 325 (1999).

6. U. Arnold: Aspects of the cytotoxic action of ribonucleases. Curr. Pharm. Biotechnol. 9, 161 (2008).

7. P.A. Leland, K.E. Staniszewski, B.M. Kim, and R.T. Raines: Endowing human pancreatic ribonuclease with toxicity for cancer cells. J. Biol. Chem. 276, 43095 (2001).

8. D. Teoli, L. Parisi, N. Realdon, M. Guglielmi, A. Rosato, and M. Morpurgo: Wet sol-gel derived silica for controlled release of proteins. J. Controlled Release 116, 295 (2006).

9. M.A. Brook, Y. Chen, Z. Zhang, and J.D. Brennan: Sugar-modified silanes: Precursors for silica monoliths. J. Mater. Chem. 14, 1469 (2004).

10. S.P. Cullen, X. Liu, I.C. Mandel, F.J. Himpsel, and P. Gopalan: Polymeric brushes as functional templates for immobilizing ribonuclease A: Study of binding kinetics and activity. Langmuir 24, 913 (2008)

11. A.N. Zelikin: Drug releasing polymer thin films: New era of surface-mediated drug delivery. ACS Nano 4, 2494 (2010).

12. R.B. Shmueli, D.G. Anderson, and J.J. Green: Electrostatic surface modifications to improve gene delivery. Expert Opin. Drug Deliv. 7, 535 (2010).

13. C.M. Jewell, S.M. Fuchs, R.M. Flessner, R.T. Raines, and D.M. Lynn: Multilayered films fabricated from an oligoarginine- conjugated protein promote efficient surface-mediated protein transduction. Biomacromolecules 8, 857 (2007).

14. A.M. Klibanov: Immobilized enzymes and cells as practical catalysts. Science 219, 722 (1983).

15. Pulsed Laser Deposition of Thin Films, edited by R. Eason (Wiley, New York, 2007).

16. D.B. Chrisey, A. Piqué, R.A. McGill, J.S. Horwitz, B.R. Ringeisen, D.M. Bubb, and P.K. Wu: Laser deposition of polymer and biomaterial films. Chem. Rev. 103, 553 (2003).

17. A.P. Caricato, M. Lomascolo, A. Luches, F. Mandoj, M.G. Manera, M. Mastroianni, M. Martino, R. Paolesse, R. Rella, F. Romano, T. Tunno, and D. Valerini: MAPLE deposition of methoxy Ge triphenylcorrole thin films. Appl. Phys. A 93, 651 (2008).

18. D.M. Bubb, P.K. Wu, J.S. Horwitz, J.H. Callahan, M. Galicia, A. Vertes, R.A. McGill, E.J. Houser, B.R. Ringeisen, and D.B. Chrisey: The effect of the matrix on film properties in matrixassisted pulsed laser evaporation. J. Appl. Phys. 91, 2055 (2002).

19. R. Cristescu, C. Cojanu, A. Popescu, S. Grigorescu, L. Duta, O.S. Ionescu, D. Mihaiescu, T. Buruiana, A. Andronie, I. Stamatin, I.N. Mihailescu, and D.B. Chrisey: Laser processing of polyethylene glycol derivative and block copolymer thin films. Appl. Surf. Sci. 255, 5605 (2009).

20. R. Cristescu, C. Popescu, A. Popescu, S. Grigorescu, I.N. Mihailescu, D. Mihaiescu, S.D. Gittard, R.J. Narayan, T. Buruiana, I. Stamatin, and D.B. Chrisey: Functional polyethylene glycol derivatives nanostructured thin films synthesized by matrix-assisted pulsed laser evaporation. Appl. Surf. Sci. 255, 9873 (2009).

21. A. Gutierrez-Llorente, G. Horwitz, R. Perez-Casero, J. Perriere, J.L. Fave, A. Yassar, and C. Sant: Growth of polyalkylthiophene films by matrix assisted pulsed laser evaporation. Org. Electron. 5, 29 (2004).

22. B.R. Ringeisen, J. Callahan, P.K. Wu, A. Pique, B. Spargo, R.A. McGill, M. Bucaro, D.M. Bubb, and D.B. Chrisey: Novel laserbased deposition of active protein thin films. Langmuir 17, 3472 (2001).

23. M.A. Hernandez-Perez, C. Garapon, C. Champeaux, P. Shahgaldia, A. Coleman, and J. Mugnier: Pulsed laser deposition of bovine serum albumin protein thin films. Appl. Surf. Sci. 208-209, 658 (2003).

24. G. Kecskemeti, N. Kresz, T. Smausz, B. Hopp, and A. Nogradi: Pulsed laser deposition of pepsin thin films. Appl. Surf. Sci. 247, 83 (2005).

25. Y. Tsuboi, M. Goto, and A. Haya: Pulsed laser deposition of silk protein: Effect of photosensitized-ablation on the secondary structure in thin deposited films. J. Appl. Phys. 89, 7917 (2001).

26. L. Stamatin, R. Cristescu, G. Socol, D. Mihaiescu, I. Stamatin, I.N Mihailescu, and D.B. Chrisey: Laser deposition of fibrinogen blood proteins thin films by matrix assisted pulsed laser evaporation. Appl. Surf. Sci. 248, 422 (2005).

27. E. György, J. Santiso, A. Figueras, G. Socol, and I.N. Mihailescu: Biomolecular papain thin films deposited by laser techniques. J. Mater. Sci.-Mater. Med. 18, 1643 (2007).

28. E. György, A. Pérez del Pino, G. Sauthier, and A. Figueras: Biomolecular papain thin films grown by matrix assisted and conventional pulsed laser deposition: A comparative study. J. Appl. Phys. 106, 114702 (2009).

29. E. György, E. Axente, I.N. Mihailescu, D. Predoi, S. Ciuca, and J. Neamtu: Creatinine biomaterial thin films grown by laser techniques. J. Mater. Sci.-Mater. Med. 19, 1335 (2008).

30. E. György, F. Sima, I.N. Mihailescu, T. Smausz, G. Megyeri, R. Kékesi, B. Hopp, L. Zdrentu, and S.M. Petrescu: Immobilization of urease by laser techniques: Synthesis and application to urea biosensors. J. Biomed. Mater. Res. 89A, 186 (2009).

31. T. Smausz, G. Megyeri, R. Kékesi, C. Vass, E. György, F. Sima, I. N. Mihailescu, and B. Hopp: Comparative study on pulsed laser 
deposition and matrix assisted pulsed laser evaporation of urease thin films. Thin Solid Films 517, 4299 (2009).

32. E. György, F. Sima, I.N. Mihailescu, T. Smausz, B. Hopp, D. Predoi, L.E. Zdrentu, and S. Petrescu: Biomolecular urease thin films grown by laser techniques for blood diagnostic applications. $J$. Mater. Eng., C 30, 537 (2010).

33. J. Bohandy, B.F. Kim, and F.J. Adrian: Metal deposition from a supported metal film using an excimer laser. J. Appl. Phys. 60, 1538 (1986).

34. Z. Kantor, Z. Toth, and T. Szorenyi: Laser induced forward transfer: The effect of support-film interface and film-to-substrate distance on transfer. Appl. Phys. A 54, 170 (1992).

35. E. Fogarassy, F. Fuchs, F. Kerheve, G. Hauchecorne, and J. Perriere: Laser induced forward transfer of high $T_{\mathrm{c}} \mathrm{YBaCuO}$ and $\mathrm{BiSrCaCuO}$ superconducting thin films. J. Appl. Phys. 66, 457 (1989).

36. A. Piqué, D.B. Chrisey, and R.C.Y. Auyeung: A novel laser transfer process for direct writing of electronic and sensor materials. Appl. Phys. A 69, S279 (1999).

37. B.R. Ringeisen, D.B. Chrisey, A. Piqué, H.D. Young, R. Modi, M. Bucaro, J. Jones-Meehan, and B.J. Spargo: Generation of mesoscopic patterns of viable Escherichia coli by ambient laser transfer. Biomaterials 23, 161 (2002).

38. P. Serra, J.M. Fernández-Pradas, F.X. Berthet, M. Colina, J. Elvira, and J.L. Morenza: Laser direct writing of biomolecule microarrays. Appl. Phys. A 79, 949 (2004).

39. P. Serra, M. Colina, J.M. Fernández-Pradas, L. Sevilla, and J.L. Morenza: Preparation of functional DNA microarrays through laser-induced forward transfer. Appl. Phys. Lett. 85, 1639 (2004).

40. J.A. Barron, P. Wu, H.D. Ladouceur, and B.R. Ringeisen: Biological laser printing: A novel technique for creating heterogeneous 3-dimentional cell patterns. Biomed. Microdevices 6, 139 (2004).

41. B. Hopp, T. Smausz, N. Barna, C. Vass, Z. Antal, L. Kredics, and D. Chrisey: Time-resolved study of absorbing film assisted laser induced forward transfer of Trichoderma longibrachiatum conidia. J. Phys. D: Appl. Phys. 38, 833 (2005).

42. A. Karaiskou, I. Zergioti, C. Fotakis, M. Kapsetaki, and D. Kafetzopoulos: Microfabrication of biomaterials by the sub-ps laser-induced forward transfer process. Appl. Surf. Sci. 208-209, 245 (2003)

43. M. Moussaoui, A. Guasch, E. Boix, C.M. Cuchillo, and M.V. Nogués: The role of non-catalytic binding subsites in the endonuclease activity of bovine pancreatic ribonuclease A. J. Biol. Chem. 271, 4687 (1996).

44. R.S. Dingus and R.J. Scammon: Grüneisen-stress-induced ablation of biological tissue. Proc. SPIE 1427, 45 (1991).

45. R. Cramer, R.F. Haglund Jr., and F. Hillenkamp: Matrix-assisted laser desorption and ionization in the $\mathrm{O}-\mathrm{H}$ and $\mathrm{C}=\mathrm{O}$ absorption bands of aliphatic and aromatic matrices: Dependence on laser wavelength and temporal beam profile. J. Mass Spectrom. Ion Processes 169(170), 51 (1997).

46. E. Leveugle, D. Ivanov, and L.V. Zhigilei: Photomechanical spallation of molecular and metal targets: Molecular dynamics study. Appl. Phys. A 79, 1643 (2004).

47. A.L. Mercado, C.E. Allmond, J.G. Hoekstra, and J.M. Fitz-Gerald: Pulsed laser deposition vs. matrix assisted pulsed laser evaporation for growth of biodegradable polymer thin films. Appl. Phys. A 81, 591 (2005)

48. H. Georg, C.W. Wharton, and F. Siebert: Temperature induced protein unfolding and folding of RNase A studied by time-resolved infrared spectroscopy. Laser Chem. 19, 233 (1999).

49. J. Kong and S. Yu: Fourier transform infrared spectroscopic analysis of protein secondary structures. Acta Biochim. Biophys. Sin. 39, 549 (2007).

50. J.F. Neault, S. Diamantoglou, M. Bearegard, S. Nafisi, and H.A. Tajmir-Riahi: Protein unfolding in drug-RNase complexes. $J$. Biomol. Struct. Dyn. 25, 387 (2008).

51. P. Del Vecchio, F. Catanzano, B. de Paola, and G. Barone: Thermodynamic stability of ribonuclease B. J. Therm. Anal. Calorim. 61, 363 (2000). 